\title{
Manuel Ancízar y la enseñanza de la economía política ${ }^{1}$
}

\author{
Germán Raúl Chaparro² \\ Universidad Central, Colombia
}

Recepción: 15/04/2020

Evaluación: 20/04/2020

Aprobación: 15/05/2020

Artículo de Investigación-Científica

DOI: https://doi.org/10.22267/rhec.202424.78

\section{Resumen}

Este trabajo analiza la contribución de Manuel Ancízar a la enseñanza de la economía política; se toma como referencia el programa del curso impartido en la Universidad Nacional de Colombia, en 1873. Este programa permite identificar influencias teóricas y temas de interés que guardan relación con el proyecto republicano que Ancízar, como gran promotor de redes de sociabilidad, divulgador de ideas, funcionario público, político y profesor, se esforzó por promover. A través del programa, los libros de texto utilizados y las disertaciones de sus estudiantes, se intenta identificar sus influencias teóricas y los problemas a los que concedió mayor importancia.

Palabras clave: Colombia; economía política; Manuel Ancízar.

1 Este artículo surge de la investigación: La enseñanza de la Economía Política en América Latina avalado por la Universidad Central, Colombia.

2 Docente de la Universidad Central, Colombia. Doctorando en Historia de la Universidad Nacional, Colombia. Grupo de investigación de Protección Social de la Universidad Nacional de Colombia, Grupo Ataralawaa Amaa de la Universidad Central, Colombia. Líneas de investigación: Protección social, Historia del pensamiento económico, Tributación. Correo electrónico: rchaparrog@unal.edu.co. (1) https://orcid.org/00000002-6443-0021 


\title{
Manuel Ancízar and the teaching of political economy
}

\begin{abstract}
This paper analyzes the contribution of Manuel Ancízar to the teaching of Political Economy. The reference is the program of the course that he taught at the National University of Colombia, in 1873. This program allows identifying theoretical influences and topics of interest related to the republican project of Ancízar. He tried to promote that program, as a great promoter of social networks, disseminator of ideas, public official, politician and teacher. With this paper, there is an attempt to identify his theoretical influences and the problems to which he attached the greatest importance, through the program, the textbooks he used and the dissertations of his students.
\end{abstract}

Keywords: Colombia; political economy; Manuel Ancízar.

\section{Manuel Ancízar e o ensino de economia política}

\section{Resumo}

Este trabalho analisa a contribuição de Manuel Ancízar para o ensino de economia política; Toma-se como referência o programa do curso ministrado na Universidade Nacional da Colômbia em 1873. Este programa permite identificar influências teóricas e temas de interesse que e estão relacionados com o projeto republicano que Ancízar, como grande promotor das redes de sociabilidade, disseminador de ideias, funcionário público, político e professor, ele se esforçou para promover. Através do programa, dos manuais utilizados e das dissertações dos alunos, procurase identificar as suas influências teóricas e os problemas aos quais atribuía maior importância.

Palavras-chave: Colômbia; economia política; Manuel Ancízar. 


\section{Introducción}

El 23 de enero de 1868, Manuel Ancízar Basterra recibió una carta de Carlos Martín, Secretario del Interior y Relaciones Exteriores, donde se le anunciaba que el gobierno del presidente Santos Acosta le ofrecía el nombramiento como rector de la Universidad Nacional de los Estados Unidos de Colombia. ${ }^{3}$ Ancízar, quien por ese entonces tenía 55 años de edad, reunía una amplia trayectoria en procesos de formación y consolidación de sociabilidad científico-cultural; había sido profesor, Secretario de Estado, presidente del Consejo de Instrucción Pública, Secretario de la Comisión corográfica, parlamentario, presidente de la Academia Nacional de Ciencias Naturales; era una figura prominente dentro del liberalismo ${ }^{4}$ y la masonería. Ancízar aceptó el reto de liderar, desde el ámbito académico, una de las aspiraciones más controversiales del radicalismo liberal: el proyecto de laicización desde la educación. ${ }^{5}$ Además de asumir el rectorado de la Universidad, continuó con su actividad docente.

La primera época de la Universidad Nacional se caracterizó por la dependencia respecto al Gobierno y la correlativa marginalidad de su autonomía, lo que implicó que los reglamentos de las escuelas y los contenidos de los programas de estudio los dictara el Gobierno (Villamil Ardila, 2001, p. 22). De esta manera, Ancízar pronto se vio envuelto en una polémica sobre el contenido de los cursos, en particular sobre el uso de textos. En cualquier caso, la injerencia del ejecutivo y la falta de compromiso en la financiación del proyecto educativo condujeron a su renuncia a la rectoría (Ancízar, 1870), aunque continuó en el ejercicio docente.

En este artículo, se analiza la contribución de Ancízar, en calidad de catedrático, a la enseñanza de la Economía Política en la segunda mitad del

3 La Ley 66, del 22 de septiembre de 1867, autorizó al gobierno para organizar una universidad en la capital de la República, ordenando que la integraran seis escuelas: Derecho, Medicina, Ciencias naturales, Ingeniería, Literatura y Filosofía, y el Instituto de Artes y Oficios. Al mismo tiempo, se adscribió a la Universidad la Biblioteca Nacional, el Observatorio Astronómico, el Museo de la Escuela de Ciencias Naturales; el laboratorio de química y los hospitales de caridad y militar.

4 Safford ha señalado que Ancízar se vinculó al conservadurismo en la década de 1840, pero transitó hacia el liberalismo durante el periodo de predominio liberal, que comenzó en 1849 (1989, p. 38).

5 La primera designación como rector correspondió a Ezequiel Rojas, quien, sin embargo, renunció al nombramiento a los pocos días. Por esta razón, Manuel Ancízar puede ser considerado el primer rector en ejercicio de la institución. 
siglo XIX; se trata de identificar, a través del Programa de economía política de 1873 , las influencias teóricas y la pertinencia del curso. Se propone que el programa ofrece luces para identificar la importancia relativa que Ancízar, y en general los escritores económicos del siglo XIX, le otorgaban, a las distintas ramas de la actividad económica y las implicaciones que esto tendría tanto sobre el desempeño económico como sobre el conjunto del orden social y la posibilidad de adaptación de los enfoques teóricos a las condiciones y posibilidades particulares de cada sociedad. Además, el ejercicio permite reconocer los antecedentes remotos de la consolidación institucional de la Economía en Colombia, que se produce a mediados del siglo XX, y contribuir a la comprensión del pensamiento económico colombiano.

El artículo se desarrolla en cuatro secciones adicionales a esta introducción. En la primera sección, se expone la metodología utilizada; en la segunda, se realiza el planteamiento del problema; en la tercera sección se presentan los resultados del ejercicio: primero, se describe, a grandes trazos, la trayectoria biográfica de Manuel Ancízar; luego, se señalan algunos antecedentes relevantes de la enseñanza de la Economía Política en el siglo XIX y, por último, se analiza en programa de Economía Política que impartió Ancízar en 1873. En la última sección se presentan las conclusiones.

\section{Metodología}

La metodología implementada en el desarrollo de este texto se estructuró en dos partes: una primera, referente a las fuentes bibliográficas utilizadas, y una segunda, atinente al ejercicio analítico-comparativo, constituido por las fuentes recién aludidas. En relación con la primera parte, se señala que se examinaron fuentes primarias, tales como los Anales de la Universidad Nacional de los Estados Unidos de Colombia (1873), con el fin de consultar el programa de Economía Política que estructuró e impartió Ancízar en su época de docente en la Universidad. Esta fuente permite examinar el contexto institucional propio del Alma Mater y sus relaciones con el entorno organizacional de las entidades del Estado colombiano relevantes. La información complementaria, correspondiente a fuentes secundarias, se constituyó por material biográfico de Ancízar, material referente al pensamiento de los primeros economistas colombianos $\mathrm{y}$, en general, al pensamiento colombiano, y el concerniente al examen 
de la situación institucional y coyuntural de la época en la cual Ancízar se desempeñó como profesor de Economía en la Universidad Nacional. De forma perentoria, se consultaron detalladamente los textos utilizados en el desarrollo de los cursos, entre otros, los Principios de Economía Política (1859), el Tratado Elemental de Economía Política Ecléctica (1845), ambos de Colmeiro, y el "Traité d'économie politique sociale ou industrielle", de Garnier (1868). Por último, pero no menos importante, se indica que se consultaron los textos de Economía Política y Estadística. Lecciones dictadas en la Universidad Nacional, del doctor Santiago Pérez (2002), el Programa para la enseñanza de la economía política en las universidades de la República, de Ezequiel Rojas (1844), y el "Programa para la enseñanza de la economía social, formado por el profesor doctor Ezequiel Rojas" (1871), ello con el fin de contar con un marco de referencia y poder apreciar las diferentes orientaciones de la enseñanza de los tres intelectuales que no solo dictaron clases de Economia en los albores de la Universidad Nacional, sino, también, fueron integrantes conspicuos del Partido Liberal, en la época del Radicalismo Liberal.

En relación con la parte correspondiente al ejercicio analíticocomparativo, el ejercicio consistió en examinar las fuentes biográficas para determinar los principales hitos profesionales (y personales, cuando incidieron en lo profesional) de la vida y obra de Manuel Ancízar. Esta acción permitió establecer un marco de referencia para estimar la trayectoria de sus principales actividades y logros, y contextualizarlos en relación con su concepción de lo que era, según él, la Economía, como, también, para relacionarla con la concepción que tenía sobre los problemas sociales concomitantes al desenvolvimiento mismo de la Economía. Como se verá, la concepción de Ancízar sobre la Economía no era economicista, es decir, reduccionista, sino, más bien, multi- o inter-disciplinar, a tal punto que llegara a afirmar que "la Economía política no es [...] sino una rama de la Antropología, reducida al estudio del hombre como animal industrioso" (1873a, p. 101).

En relación con el Plan de estudios propiamente dicho, estructurado e impartido por Ancízar, el ejercicio analítico-comparativo consistió en examinar el material provisto y aplicado por los profesores Rojas y Pérez, con el fin de determinar un marco de referencia sencillo para poder precisar posibles similitudes o diferencias entre las concepciones de estos profesores respecto a la del profesor Ancízar. En este sentido, el ejercicio permitió 
determinar los puntos de énfasis de los respectivos cursos y, de forma concomitante, las posibles aplicaciones y, en últimas, la utilidad potencial del material ofrecido a los profesionales en proceso de formación.

Por su parte, el análisis detallado del Plan de estudios estructurado e impartido comportó el estudio de cada uno de los manuales que utilizó el profesor Ancízar en las clases de la Universidad Nacional. Puntualmente, el ejercicio correspondió a la revisión del contenido de cada uno de los textos, análisis de los temas, su pertinencia, el tratamiento pedagógico, el examen del alcance de los contenidos (vale decir, grado de profundidad y complejidad), grado de concatenación, posibilidades de aplicación a la realidad de la Colombia Federal de la época, y posibles limitaciones. Claramente, el examen de los textos utilizados se apoyó en el análisis de material adicional atinente a la concepción de Ancízar acerca de los aspectos técnicos, el estudio de la economía propiamente dicho, por ejemplo, el funcionamiento de los mercados, y las asuntos correspondientes a la moral, habida cuenta del papel central que desempeña en el ser humano en tanto formador y tomador de decisiones; en realidad, Ancízar no creía que el ser humano fuera un simple homo oeconomicus, que solo piensa en función de lo económico, toda vez que esto adulteraría la representación y concepción de su naturaleza en tanto ser social.

Por último, pero no menos importante, es relevante mencionar que el examen, análisis y comparación del material consultado también incluyó un análisis correspondiente a la coyuntura histórica y a los principales rasgos institucionales, tales como el "espíritu católico" del pueblo colombiano de la época del Liberalismo Radical.

\section{Planteamiento del problema}

En este texto, se considera que el conocimiento acerca de la enseñanza de la Economía política, en la segunda mitad del siglo XIX, puede ofrecer elementos importantes para estimar los efectos y posibles impactos en la formación de los estudiantes de la Nacional en sus albores, como, también, en su desempeño y utilidad una vez en ejercicio profesional. Específicamente, se mantiene que las influencias teóricas y la pertinencia misma del contenido de la enseñanza de la Economía pudo tener alguna influencia en la formación de los futuros profesionales, concretamente en sus concepciones de los fenómenos económicos así como en los 
concomitantes fenómenos y problemas sociales, todo lo cual terminó por incidir en algún grado en la pertinencia y calidad de las intervenciones estatales, como quiera que los profesionales en proceso de formación tendrían que ver directa o indirectamente con la gestión pública (estatal) y, por tanto, su ejercicio terminó por incidir en el desempeño económico y, en general, en el conjunto del orden social.

De conformidad con esto, establecer la estructura del contenido del programa de enseñanza ayuda a estimar de forma indicativa el tipo de profesional que producía decisiones, elaboraba conceptos sobre asuntos de intervención pública y brindaba asesoría a entidades privadas. Igualmente, su conocimiento ofrecería pistas sobre las razones de su accionar, concepciones de política económica y de fenómenos sociales asociados. Por esto, el conocimiento del programa de estudio considerado ofrece una estimación indicativa acerca de la contribución del profesor Ancízar a la enseñanza de la economía en el país.

\section{Resultados}

\subsection{Un bosquejo biográfico de Manuel Ancízar}

Manuel Esteban Ancízar Basterra (1811-1882) fue el menor de cuatro hijos, de la unión de José Francisco Ancízar y Juana Bernarda Basterra, dos españoles que llegaron a Santafé de Bogotá en la comitiva del virrey Antonio Amar y Borbón, en 1803. La familia Ancízar-Basterra se vio obligada a preparar su escape, tras los acontecimientos del 7 de agosto de 1819, por lo cual marcharon hacia Cartagena con el fin de abandonar posteriormente el país, un camino marcado por tribulaciones y muerte. Con tan solo siete años de edad, Manuel Ancízar tuvo que presenciar cómo, en el trayecto, morían su tía materna y dos hermanos y, ya en Cartagena, un reducto realista asediado por los patriotas, la muerte de su hermana (Loaiza Cano, 2004, p. 12). En 1821, los tres miembros sobrevivientes de la familia arribaron a Cuba; allí el padre, ahora agricultor, logró arreglárselas para que su hijo estudiara Derecho en la Real Pontificia Universidad de San Gerónimo (Loaiza Cano, 2004, p. 17). En 1824, murió doña Juana Bernarda Basterra y, en 1832, don José Francisco Ancízar.

Manuel Ancízar se educó en Cuba, en tiempos de aires de renovación del pensamiento filosófico, político y jurídico cubano, debido a la influencia 
de la Ilustración francesa y la relativa facilidad para acceder a libros procedentes de editoriales estadounidenses, como las obras de Washington Irving y Benjamín Franklin, y el acceso a traducciones al español de las obras de Victor Cousin, y de sus discípulos Felipe Damiron y Théodore Simon Jouffroy, a través de los cuales se aproximó a la influencia del eclecticismo francés. También tuvo acceso a reimpresiones de libros de Bentham, Coleridge, Adam Smith y Carlyle, autores que no formaban parte del plan de estudios universitario.

Jaime Jaramillo Uribe, en su obra El pensamiento colombiano en el siglo XIX, atribuye a Rafael Núñez, Miguel Samper y Manuel Ancízar, el esfuerzo de "corrección de las fórmulas del liberalismo romántico y radical de ascendencia francesa, con un liberalismo de origen inglés" (2001, p. 116) y señala que las influencias francesa e inglesa fueron decisivas en la orientación política del pensamiento colombiano del siglo XIX: Ancízar, al igual que Samper, se formaron "esencialmente en la escuela de los negocios, en la lectura de escritores ingleses y en la observación de la historia política de la Gran Bretaña" (Jaramillo Uribe, 2001, p. 171), lo cual implica una propensión a evitar trasladar las premisas del liberalismo económico al campo político y aceptar la intervención del Estado para garantizar la armonía en el campo de las relaciones políticas y sociales.

Gilberto Loaiza ha propuesto que Manuel Ancízar despreciaba el modelo político británico y que, más bien, se caracterizó por "su encantamiento, casi acrítico con la democracia norteamericana" (2004, p. 68). La lectura de autores ingleses habría sido producto de la curiosidad intelectual, pero no definió necesariamente sus inclinaciones filosóficas y su pensamiento político. Leyó a Bentham, Condillac y Destutt de Tracy; a partir de este último, se familiarizó con las tesis sensualistas, para, luego, a través de la lectura de Victor Cousin, inclinarse casi definitivamente hacia el espiritualismo. ${ }^{6} \mathrm{Su}$ formación intelectual liberal pronto entró en conflicto con las restricciones que imponía el sistema colonial sobre las libertades individuales.

${ }^{6}$ En la segunda mitad de la década de 1810, en Francia se presentó una reacción política contra los legados de la Revolución. El movimiento político de los doctrinarios, liderados por François Guizot, implicó la revisión del pensamiento de los ideólogos, representados por Destutt De Tracy y Pierre Cabanis, caracterizados por el sensualismo, en favor de una filosofía del espiritualismo ecléctica, promovida por Pierre-Paul Royer-Collard y Victor Cousin, consistente en un intento de conciliar el racionalismo cartesiano, el empirismo sensualista, la filosofía del sentido común y el idealismo. 
En un contexto en el que proliferaban las logias masónicas y las sociedades secretas, en las que Ancízar parece haber participado, todavía más, resultó involucrado en un proyecto conspirativo, que promovía la emancipación de Cuba (Loaiza Cano, 2004, p. 31). En ese momento, la mezcla de un espíritu liberal, sus vínculos con la masonería y los señalamientos como conspirador provocan en Ancízar la conciencia de la influencia potencial que su presencia podría tener en su país de origen y empezó a considerar la posibilidad del retorno. Por ello, decidió escapar al régimen colonial cubano; primero, viajó a Estados Unidos, donde conoció las principales ciudades norteamericanas y reafirmó sus convicciones republicanas (Otero Muñoz, 1940, p. 6).

En 1839, Manuel Ancízar viajó a Venezuela a reemplazar a Fermín Toro en la cátedra de filosofía del Colegio de la Independencia, en Caracas. Allí, sus convicciones liberales y su pasión por tener influencia pública lo llevaron a participar activamente en la promoción de proyectos culturales y estimular una sociabilidad intelectual amparada por el Estado. Ancízar fue presidente del Liceo de Caracas, revivió un Decreto de 1833 sobre la creación de una Biblioteca Nacional y organizó la creación de la revista El Liceo Venezolano.

Si bien, en Cuba, Manuel Ancízar había sido espectador de la polémica en torno a las nuevas corrientes filosóficas, en Venezuela estaba llamado a ser protagonista. En ese entonces, Fermín Toro, defensor de espiritualismo francés, se encontraba polemizando con Rafael Acevedo, difusor del sensualismo de Condillac y De Tracy. Ancízar siguió la senda de Toro y, el 2 de septiembre de 1839, en la lección inaugural de la cátedra, leyó a sus estudiantes un mensaje anti-sensualista, donde afirmaba la preeminencia de las ideas innatas y exaltaba la razón como facultad absoluta y superior. Evidentemente, tanto Ancízar como Acevedo emprendieron una disputa por imponer contenidos y métodos de enseñanza para difundir una u otra tendencia filosófica.

En marzo de 1841, Manuel Ancízar se trasladó a la ciudad de Valencia, donde lo nombró la Dirección General de Instrucción Pública como rector del Colegio Nacional de Carabobo, una institución con panorama sombrío, dada la escasez de recursos, de alumnos y de profesores competentes, amén del menosprecio de la comunidad local. No obstante, el liderazgo de Ancízar, en la creación de redes de sociabilidad, permitió que, bajo su influjo, surgieran la Sociedad Patriótica de Carabobo, una Caja de Ahorros y el periódico El Siglo: 
"Todo su despliegue tenía como propósito crear vida social, movimiento económico, institucionalidad cultural, agitación de ideas, divulgación del conocimiento científico" (Loaiza Cano, 2004, p. 56). En conclusión, según Loaiza Cano, en Venezuela, Manuel Ancízar tuvo la oportunidad de ejercer su influjo de hombre liberal, organizador de redes de sociabilidad y educador (p. 65).

El retorno a su país de origen se empezó a concretar a comienzos de 1845, cuando regresa a Caracas para asumir las funciones de Ministro plenipotenciario ad hoc por la Nueva Granada ante el gobierno venezolano, con la misión de resolver un conflicto de fronteras entre los dos países. El mentor de su retorno fue Lino de Pombo, con quien Manuel Ancízar había establecido correspondencia desde 1842, cuando aquél era Enviado diplomático del gobierno del presidente Pedro Alcántara Herrán. A pesar de sus diferencias ideológicas, Ancízar y Pombo fueron cercanos en el propósito de fomentar la educación técnica del pueblo y formar unas élites administradoras del sistema republicano.

El retorno definitivo de Manuel Ancízar a su país natal se produjo en 1846; allí incursionó rápidamente en cargos del gabinete ministerial del presidente Tomás Cipriano de Mosquera, quien, en septiembre de 1846, lo nombró subsecretario del despacho de Relaciones Exteriores y Mejoras Internas. Ancízar comenzó a asumir la misión de construir y fundar sobre principios racionales y científicos la actividad política para darle fisionomía sólida y permanente a la República y a la construcción de una sociedad moderna dentro de los vaivenes del siglo XIX (Loaiza Cano, 2004, pág. 105). Una de sus tareas fue promover la llegada de científicos extranjeros; así, arribaron al país personajes como el químico napolitano José Éboli y el arquitecto escocés Thomas Reed, enviados desde Venezuela por Ancízar, y poco después intercedió para que llegara el coronel Agustín Codazzi. A ellos se unieron el francés Antonio Poncet, director general de caminos; Carlos Segismundo de Greiff, encargado de adelantar exploraciones en la región de Urabá, y Estanislao Zawadsky, a quien le correspondió abrir caminos en la región de Buenaventura. También se destaca el esfuerzo en la vinculación del sacerdote jesuita Ignacio Gomila, procedente de Chile, en la enseñanza de las ciencias naturales (Loaiza Cano, 2004, pág. 106).

Sin embargo, la Nueva Granada no había logrado superar el proceso de transición del orden colonial al nuevo orden republicano, régimen que se debatía en enfrentamientos frecuentes entre facciones federalistas y centralistas, conflictos civiles que expresaban diferencias regionales 
profundas y un clima de inestabilidad política; además, tomaba relieve un clima de reacción republicana contra las tradiciones coloniales. En ese contexto, Ancízar asume el reto de promover una organización civil que respondiera a las necesidades de la realidad social, la construcción de un ideario americano (Otero Muñoz, 1940, p. 8-10). El periódico El Neogranadino, que creó en 1849, se convirtió en tribuna de conciliación entre las facciones políticas que se disputaban el poder, y el libro Lecciones de psicología, publicado en 1851, le permitió plasmar sus convicciones filosóficas, en uno y otro caso comprometido con la defensa de la libertad de pensar, sentir y obrar según lo determinase la razón. Como ha señalado Gustavo Otero Muñoz, Ancízar se propuso como empresa una "utopía republicana", un proyecto basado en la "tolerancia política" en un contexto dominado por "pasiones primitivas", lo que resultaba lógicamente inviable (p. 12). Poco tiempo después, nuestro protagonista toma algo de distancia y se concentra en su participación en la Comisión Corográfica.

Ancízar también se destacó en la promoción de sociedades filantrópicas, la contratación de profesores extranjeros y la difusión de "conocimientos útiles" a partir de la capacitación técnica (1989, p. 103104); por ejemplo, como Subsecretario de Estado, durante la presidencia de Mosquera, promovió la fundación del Instituto Caldas, una corporación patriótica que tenía por objeto fomentar "el desarrollo de la inteligencia, la conservación de la moral y el perfeccionamiento de la industria en el pueblo granadino", con secciones en cada capital de provincia, organizadas "según las necesidades y recursos de cada provincia" (Presidencia de la Nueva Granada, 1847). El instituto lo conformaban cuatro secciones de educación, beneficencia, mejoras materiales e inmigración, estadística y comunicación; cada una de ellas buscaba, en distintas esferas de acción, reformar las costumbres, corregir hábitos, establecer modelos y mejorar los métodos de producción. El Instituto Caldas fortaleció una red de producción y circulación del conocimiento (Del Castillo, 2018, p. 132). Ancízar también fue promotor de una ley gubernamental para fomentar la inmigración de europeos provenientes de países no católicos, con libertad para "el ejercicio público" de sus cultos, ${ }^{7}$ propuesta semejante a la impulsada en Venezuela por Codazzi, con la Colonia Tovar. Al proyecto lo criticaron

7 Ley del 12 de junio de 1847, que autorizaba a los agentes neogranadinos en el exterior para celebrar contratos con empresarios, y al Poder ejecutivo para repartir tierras baldías entre inmigrantes europeos. 
los sectores más conservadores y clericales del país. La conformación de un grupo de científicos y técnicos extranjeros correspondió con la intención de promover los estudios de diversas ciencias. El intento de patrocinar el arribo paulatino de miembros de comunidades religiosas diferentes a la católica señalaba el ánimo secularizador que acompañaría a Ancízar durante toda su trayectoria política (Loaiza Cano, 2004, p. 108).

Más evidente aún es el influjo de Ancízar en la creación de la Escuela Práctica de Arquitectura, donde Reed adelantó la tarea de construir el Capitolio Nacional. Ancízar argumentó la necesidad de promover en el país "artes eminentemente útiles". ${ }^{8}$ Además de promover estudios prácticos, carreras útiles, tanto para la élite como para los artesanos neogranadinos, concebía la necesidad de instruir a los individuos en aquellos conocimientos que contribuyeran a explotar racionalmente los recursos naturales de cada región, idea que desarrolla en Peregrinación de Alpha (1853). ${ }^{9}$ Ancízar abandonó la Comisión Corográfica en 1852, cuando lo nombraron diplomático en Ecuador, Perú y Chile. ${ }^{10}$

\subsection{La enseñanza de la Economía Política en el siglo XIX: un bosquejo}

El interés por el rumbo económico de la nueva República comienza con los llamados economistas coloniales: Antonio de Narváez y la Torre, José Ignacio de Pombo, Pedro Fermín de Vargas (Rodríguez Salazar, 1989 y 1990), y continúa con las controversias en materia de política económica que animaron a destacados hacendistas, como: Florentino González, Salvador Camacho Roldán, Aníbal Galindo y Miguel Samper (Chaparro y Gallardo, 2015). Las fuentes de pensamiento en las que se basaban las

8 Ancízar, "Escuela de arquitectura", Gaceta de la Nueva Granada, No. 928, Bogotá, 14 de noviembre de 1847, p. 730.

9 En este libro, Ancízar describe los viajes realizados con la Comisión Corográfica que, bajo las órdenes de Agustín Codazzi, debía levantar la carta geográfica de la República. Ancízar tuvo como tarea la narración literaria y científica de los trabajos y excursiones de la Comisión; la formación de un diccionario geográfico-etnográfico; y de otro económico-estadístico; además de varias memorias sobre geología, orografía, hidrografía y sobre las antigüedades del país (Samper, 2007, p. 14).

${ }^{10}$ Su reemplazo en la Comisión fue Santiago Pérez Manosalva, quien publicó en 1853 sus observaciones y estudios de las provincias de Antioquia, Medellín y Córdoba, que se han recopilado con el título de Apuntaciones de un viaje por Antioquia y las Provincias del Sur. 
medidas económicas propuestas y la interpretación sobre la estructura productiva se pueden evidenciar a través de la enseñanza de la Economía Política.

El curso de Economía Política apareció en Colombia con el Plan de Estudios de 1826 (Art. 171), en el que se establece como materia obligatoria en los estudios de Jurisprudencia que se impartían en los colegios mayores de San Bartolomé y el Rosario, y se señala como libro de texto para el desarrollo del curso la obra clásica de economía política de Jean-Baptiste Say. ${ }^{11}$ El primer catedrático de este curso fue Francisco Soto, ${ }^{12}$ a quien pronto lo reemplazó Ezequiel Rojas, el personaje más importante en la enseñanza de la Economía Política en el país a lo largo del siglo XIX, aunque, también, se destacaron figuras como Manuel Ancízar y Santiago Pérez, los tres muy influyentes en los procesos de sociabilidad académica y en la vida política, en particular como ideólogos del liberalismo colombiano.

Respecto a la influencia teórica de estos autores, se debe señalar que, desde muy temprano, la juventud republicana entró en contacto con la filosofía de Jeremy Bentham y Destutt de Tracy y, luego, se acercó al positivismo de Saint-Simon, Augusto Comte y Herbert Spencer y al utilitarismo de John Stuart Mill. Estos acercamientos se conjugaron con la influencia de la Escuela clásica en Economía, en particular a través de la interpretación de Say y, en menor medida, las contribuciones de Thomas R. Malthus y de Frédéric Bastiat (Arévalo Hernández, 2002, p. 26-27). Ezequiel Rojas dedicó su vida a la enseñanza del utilitarismo, la ideología y la economía política; se lo considera el primer ideólogo del partido liberal, por la publicación del artículo "La razón de mi voto", en El Aviso, en 1848. También, fue importante la redacción de un proyecto de Constitución para Cundinamarca, que pudo influir sobre la Constitución de Rionegro, de 1863. Aunque, en la historiografía del pensamiento político colombiano en el siglo XIX, lo han juzgado como un replicador acrítico de las ideas económicas procedentes de Europa a un contexto, por lo demás, inadecuado (Jaramillo Uribe, 2001), en años recientes se ha reconocido

\footnotetext{
${ }^{11}$ Además, establece que también se podría usar "el resumen de su cartilla política". En el mismo Plan de estudios se establece que las clases de principios de legislación universal y de legislación civil y penal deberían seguir los tratados de legislación civil y penal de Bentham, obras que dos años más tarde las prohibiría Bolívar, mediante Decreto del 12 de marzo de 1828.

${ }^{12}$ Gaceta de Colombia, No. 275, Bogotá, 21 de enero de 1827, p. 2.
} 
su importancia a partir de la reivindicación de la tradición sensualista procedente de Francia, que propone una filosofía social para el estudio del funcionamiento de la sociedad (Hurtado, 2016). En este sentido, a Rojas lo influyen el utilitarismo de Bentham y la ideología de Tracy y Condilac que, en el terreno de la Economía Política, se expresan en los trabajos de Say. Los programas de Economía Política (Rojas, 1844) y Economía Social (Rojas, 1871) evidencian la influencia de esta tradición en su adhesión a la teoría del valor utilidad, al método empirista y a la relación entre Economía y moral (Hurtado, 2016, p. 64).

Otro aporte importante a la divulgación de la teoría económica a través de la cátedra lo representó Santiago Pérez Manosalva, quien fue convencionista de Rionegro en 1863, opositor al régimen del General Mosquera y elegido presidente de la República a la edad de 44 años. Su oposición al gobierno de Núñez y Caro provocó su destierro en 1895 y su posterior establecimiento en París, donde murió en 1900. Dentro de su obra académica en el terreno de la Economía figura un Manual de Economía Política y un diálogo sobre la conveniencia civilizadora del ahorro (Sanín Cano, 1944, p. 149). Pérez fue profesor de Economía Política en la Universidad del Rosario, donde reemplazó como catedrático a Ezequiel Rojas, en el año 1869; la Universidad Nacional, en la que lo nombraron rector en 1877; y el Externado, donde lo invitaron a compartir la dirección de la universidad en 1892, luego de un destierro voluntario de cerca de ocho años en los Estados Unidos (Correa Restrepo, 2002, p. 14).

De sus cursos en la Universidad Nacional, se conservan dos manuscritos de las notas de clase de sus alumnos, el Programa Analítico de Economía Política, escrito por Julio Duarte y Ezequiel Rojas, ${ }^{13}$ en 1880; y Economía Política y Estadística, elaborado por Manuel Pinzón y Estanislao Fajardo (Pérez Manosalva, 2002). Los apuntes de clase del curso impartido por Pérez son similares en estructura y contenido de algunas definiciones al Tratado de Economía Política de Jean Baptiste Say, publicado originalmente en 1803, a cuyas ediciones, a partir de la década de 1820, las enriquecían con un epítome de los principios fundamentales de la Economía Política (Say, 1821); en los apuntes, que siguen la forma de epítome, se presentan los conceptos básicos utilizados a lo largo del texto. Los capítulos iniciales, más

${ }^{13}$ Este alumno de Pérez es homónimo de José Ezequiel Rojas Ramírez. El que se menciona en este pasaje llevó las enseñanzas de Pérez a la Universidad de Antioquia, donde posiblemente se siguió el mismo esquema (Correa Restrepo, 2002, p. 15). 
las secciones de cambio, valor y comercio, denotan la influencia de Bastiat (Arévalo Hernández, 2002, p. 32). Los módulos de moneda, crédito y bancos están en correspondencia con el tratamiento que establece Say de la moneda y sus signos representativos que, según este autor, se trata de la producción de unos bienes particulares. El texto continúa con los temas de distribución y consumo, "en los que es fácil observar la adopción de la estructura del Tratado de Say" (Arévalo Hernández, 2002, p. 33). Adicionalmente, el texto trae un capítulo sobre población, que resume los argumentos de Malthus; y uno sobre la división del trabajo, en el que se realiza una síntesis de las ideas de Smith. La influencia del utilitarismo se torna evidente en la concepción del valor-utilidad, que defendían Bastiat y Say.

\section{a. Ancízar y el programa Economía Política de 1873}

La Facultad de Jurisprudencia de la Universidad Nacional surge de la incorporación del Colegio Mayor de San Bartolomé a la Universidad, a partir de enero de 1868, como parte del aporte del Estado de Cundinamarca a la organización de la nueva universidad. El Estatuto de la Universidad definió el Plan de Estudios, dentro del cual estaba el curso de Economía Política y Estadística, que debía impartirse en el tercer año del programa. En ese espacio académico, se nombró como catedrático principal a Ezequiel Rojas y, como sustituto a Pedro Restrepo. Por su parte, a Manuel Ancízar lo nombran docente principal del curso de Derecho Internacional y Tratados Públicos.

En 1870 se reabrió la discusión sobre los textos de enseñanza del Derecho y la Filosofía. Las obras de Bentham y De Tracy fueron una vez más objeto de debates, como lo habían sido en el pasado entre Bolívar y Santander, a propósito de la llamada querella benthamista. ${ }^{14}$ En esta oportunidad, se tramitó en el Congreso un Proyecto de ley sobre la enseñanza en la Universidad Nacional, en el que, entre otras cosas, se pretendía definir como textos de estudio de filosofía elemental la obra de Desttut De Tracy, y para principios de legislación, pruebas judiciales, organización judicial y táctica parlamentaria la obra de Jeremy Bentham. El debate suscitó una discusión que enfrentó a Ezequiel Rojas con Manuel Ancízar, que se trató de zanjar

\footnotetext{
${ }^{14}$ Una selección de los textos históricos respecto a la enseñanza de Bentham en el país la realizó Luis Horacio López (1993).
} 
mediante el nombramiento de una Comisión integrada por Miguel Antonio Caro (profesor de latín y griego), Francisco Eustaquio Álvarez (profesor de filosofía elemental) y Manuel Ancízar, razón por la cual renunció a la rectoría para poder participar en la Comisión. El resultado fue la adopción de los textos y la renuncia definitiva de Manuel Ancízar a la rectoría de la Universidad Nacional de los Estados Unidos de Colombia, el 3 de febrero de 1871 (Villamil Ardila, 2001, p. 31). En 1873, a Ancízar lo nombran profesor de Economía Política y utiliza como texto guía para el desarrollo del curso el libro de Manuel Colmeiro, Principios de Economía Política, y propone como libro de consulta el Traité d'Economie Politique Sociale ou Industrielle, de Joseph Garnier, textos que aprobó la Junta de Inspección y Gobierno en su sesión de 27 de marzo (Ancízar, 1873a, p. 105).

La selección de estos textos es un indicio de las inquietudes y el pensamiento de Ancízar en materia económica por esos años. La implementación de las reformas liberales decimonónicas, las dificultades para consolidar los auges efímeros de los productos de agroexportación imponen a los contemporáneos las preguntas sobre la importancia relativa que debería otorgarse a las distintas ramas de la actividad económica y las implicaciones que esto tendría tanto sobre el desempeño económico como sobre el conjunto del orden social, la adaptación de las oportunidades económicas a las condiciones y posibilidades de cada sociedad y la búsqueda de respuestas al pauperismo creciente, que abre las puertas a las doctrinas socialistas. En cierto sentido, se demandaba la rectificación del proyecto de sociedad liberal.

La selección del libro de Colmeiro como texto guía puede entenderse en el sentido que se refiere a un tratado ecléctico, que se separa de la tradición de la Economía Política clásica y del dogmatismo filosófico; en particular, se cuestiona la inflexibilidad del espíritu de sistema de las teorías económicas, su exceso de raciocinio y su falta de observación y de experiencia.

Manuel Colmeiro y Penido (1818-1894) fue un abogado y político liberal español, influido por el liberalismo económico de Adam Smith (1723-1790), que se conoce en España a través de autores franceses como Jean Baptiste Say (1767-1832), Joseph Droz (1773-1850) y Pellegrino Rossi (1787-1848), este último de origen italiano, pero nacionalizado en Francia en 1834. Colmeiro tradujo los Principios de la economía política, o principios de la ciencia de la riqueza, de Joseph Droz, un tratado 
elemental que había contribuido a popularizar la Economía Política en el medio académico francés, obra originalmente publicada en 1829 y cuya traducción se presentó en castellano en 1842. Dos años antes, Pedro de Madrazo había presentado la traducción del Curso de Economía Política de Rossi, escrito en el año escolar 1836-1837 (Madrazo, 1840).

Colmeiro destaca, del libro de Droz, la importancia que le concede al desarrollo de las Ciencias físicas y al método basado en la observación y la experiencia (1842, p. III), que contrapone a las doctrinas morales que, a partir de principios absolutos y con una investigación puramente especulativa, conducen a la "veneración supersticiosa" de un sistema de creencias (1842, p. V); allí, Colmeiro identifica una tensión dialéctica entre el empirismo puro, que ignora principios morales, y el dogmatismo de los sistemas morales, que niega el diálogo con la diversidad de opiniones, que proceden de la variedad de sistemas de Economía Política y que, en definitiva, impide el avance del conocimiento económico.

Para eliminar el sectarismo, Colmeiro, que sigue a Rossi, propone como solución de continuidad buscar el consenso de la diversidad de enfoques en la Economía Política alrededor de dos principios básicos de convergencia: el primero de ellos es reconocer la satisfacción de necesidades como objetivo central de la actividad económica y, el segundo, el precepto según el cual el trabajo y el ahorro son los medios que permiten la acumulación de capital; luego, permiten multiplicar la riqueza (1842, p. VIII). Colmeiro reconoce que Smith "hallo una ley común, la ley del trabajo, sin el cual no hay riqueza posible" (1842, p. XX).

En el siglo XVIII, una clase media, la burguesía naciente, conquistó un puesto privilegiado dentro del sistema industrial y, en general, dentro de la sociedad. En ese escenario, Colmeiro identifica dos peligros en la reflexión económica de la escuela clásica: el refinamiento del materialismo y el espíritu de sistema. El primero implica conceder preeminencia a los intereses mercantiles como móvil de la conducta humana y centrar la atención casi exclusivamente en ellos, lo que genera un "culto de los intereses materiales". El espíritu de sistema consiste en la pretensión, que Colmeiro atribuye a "los discípulos más celosos de Smith", de ensanchar la frontera de la naciente ciencia económica "hasta abarcar el sistema social entero y luego no vean en la sociedad sino un vasto mercado" (1842, p. XXII-XXIII). Se trata de una teoría de la concurrencia universal, fruto de un sistema de libertades industriales ilimitadas, que exhibe un incremento 
notorio de la producción de riqueza y asume su distribución espontánea. Un mecanismo que absorbe el pensamiento de los economistas, quienes olvidan la deuda social que acumula el sistema, de allí la aparición de una demanda social por el estudio de la "riqueza relativa" (1842, p. XXIV).

El progreso material de unos sectores arrastra tras de sí un cúmulo de miserias. Tras las grandes fortunas de los especuladores, se puede observar, dice Colmeiro, "que sigue el fúnebre cortejo de la miseria y la depravación de la clase obrera, y desde entonces se ha enconado la profunda llaga del pauperismo, ese cáncer que corroe y contamina los cuerpos sociales más robustos en apariencia" (1842, p. XXV). ${ }^{15}$ Esta violencia del sistema industrial contra la clase trabajadora y una masa de desposeídos contrasta con la cantidad de concesiones otorgadas a las clase privilegiadas; allí Colmeiro identifica una respuesta espontánea de los sectores vulnerados, fruto de "su propia conservación" y los "eternos principios de justicia", y que amenaza a una "catástrofe" que debe anticiparse, para lo cual se requiere "una nueva organización al trabajo", fundamentada en la idea de que la utilidad del progreso material radica en que la riqueza beneficiase a quienes concurrieron a su formación: "Esta es la cuestión vital del siglo XIX, y a resolverla se ha lanzado la escuela socialista" (1842, p. XXV-XXVI). Colmeiro reconoce a Sismondi como precursor del socialismo; este autor identifica que la sociedad se ha dividido en dos fracciones: por un lado, un grupo social que acumula la riquezas, las luces, el bienestar y, en fin, todos los dotes de la civilización, "guarecidos de egoísmo, fruto amargo del culto de los intereses materiales", y, por otra parte, una clase social humillada y proscrita, "extenuada de trabajo, cuyo fatal destino es labrar con sus manos fortunas gigantescas y en recompensa arrastrarse en la miseria, vegetar en la estupidez y en la inmoralidad y darse a la crápula y al crimen" (1842, p. XXVI). Alrededor de Sismondi se conformó un grupo, principalmente de economistas franceses, que "fundaron una escuela eminentemente social y moralizadora: hija de una reacción del espiritualismo contra el materialismo" (1842, p. XXVI), corriente de pensamiento que comúnmente se denominó economía social, a la que pertenece Droz.

Droz presenta a la Economía política como una ciencia social que fomenta los intereses materiales, morales e intelectuales, en contacto y en

${ }^{15}$ En este punto, Colmeiro sigue a Jérôme-Adolphe Blanqui (1798-1854), un discípulo de Say, autor de Histoire de l'économie politique en Europa, publicada en 1837, y una "Bibliografía razonada". 
armonía unos con otros. Divide el campo de estudio de la Economía en dos grandes temas: producción y distribución (1842, p. XXVII). La economía social se propone como fin el interés general y, en consecuencia, concibe a la riqueza como un medio para buscar la felicidad de un pueblo. Al respecto, señala Droz (1829): "La riqueza son todos los bienes materiales que sirven a las necesidades de los hombres" (p. 7). Colmeiro nos recuerda que, según Droz: "«la felicidad de un pueblo depende menos de la masa de riquezas que posee que del modo como se hallan repartidas»" (1842, p. XXVII) y que, además, cuestiona al industrialismo: "«al leer ciertos economistas casi llega uno a persuadirse de que los productos no son para los hombres, sino los hombres para los productos»»" (1842, p. XXVIII) ${ }^{16}$

Entonces, esta corriente de pensamiento propone "amoldar el sistema industrial sin destruirlo"; reconoce el trabajo como "fuente inagotable de riqueza" y tampoco niega "el poderoso influjo de la división del trabajo y de la maquinaria en la formación de las riquezas" (1842, p. XXVIII), pues las tensiones sociales, producto de la desigualdad y la pobreza, se les presentan como evidentes:

Y nótese que la escuela socialista es el espejo de la sociedad moderna convertida en un palenque abierto al combate entre el egoísmo de la aristocracia fabril y las exigencias invasoras de la democracia obrera, exigencias sostenidas con toda la energía de que son capaces las turbas acosadas del despecho, del hambre y de la desesperación, apoyadas en millares de brazos endurecidos en la fatiga, sancionadas con la emancipación que proclaman y subversivas como quien escribe en sus banderas el lema ¡abajo la propiedad! (Colmeiro, 1842, p. XXVIII-XXIX).

Colmeiro plantea que, en el contexto del siglo XIX, se requiere de tolerancia y flexibilidad de los sistemas de economía política, de los sistemas mercantil, agrícola, industrial y socialista, pues el conocimiento aplicado demanda que se combinen elementos de las distintas doctrinas; por ello, propone como necesidad que la "escuela es la ecléctica", que suavizara las asperezas de las doctrinas absolutas y se desprendiera de todo espíritu de sistema (1842, p. XXIX). Considera a Rossi como ecléctico (1842, p.

${ }^{16}$ Colmeiro está citando a Droz; el texto cuya traducción está presentando, sin embrago, al interior del libro, en el pasaje correspondiente cambia la palabra "producción" por "riqueza". Droz, en la versión original, utiliza la primera: "En lisant certains économistes, on croirait que les produits ne sont pas faits pour les hommes, et que les hommes son faits pour les produits" (Droz, 1829, pág. 76). Este detalle puede reforzar la idea de que, según Colmeiro, la riqueza es real y consiste en los productos que satisfacen necesidades. 
XXX), se refiere al Curso de economía política traducido por Pedro de Madrazo, y destaca la utilidad de la división de la Economía política en racional y aplicada, como propone Rossi, por su potencial para conciliar las teorías con sus aplicaciones y evitar confundir las tendencias con los hechos (1842, p. XXX).

En 1845, se publicó en Madrid la primera versión del libro de Economía de Colmeiro, Tratado elemental de economía política ecléctica (1845), una obra que, luego, complementó y corrigió en el libro Principios de economía política $(1859 / 1870)^{17}$ y que, después, presenta en varias ediciones corregidas y aumentadas, en 1865,1870 y 1873 , en las que se identifica la evolución de un pensamiento ecléctico. En los Principios, el autor se propone divulgar la Economía política y despojarla de la aspereza de los razonamientos abstractos; exponer las doctrinas en un "estilo llano y agradable y confirmar el discurso con ejemplos", con la intención de "escribir un libro de enseñanza y no de polémica" (Colmeiro, 1859/1870, p. VI-VII).

Colmeiro define a la Economía política como la ciencia de lo útil, y a la Moral como la ciencia de lo lícito y honesto (1859/1870, p. 11), cuyo objeto es la riqueza y su fin la promoción del bien común; y la divide en la observación de cuatro aspectos: las leyes de la producción y distribución, del cambio y del consumo de la riqueza (1859/1870, p. 9) y, aunque se establece un ámbito particular para la Economía política, asociado al estudio de la riqueza y prosperidad material de los pueblos, la considera cercana a las Ciencias morales y políticas Peiró Martín y Pasamar Alzuria, 2002.

El libro se estructura en cuatro partes: producción, circulación, distribución y consumo, cada una de las cuales se fueron ampliando en las ediciones sucesivas. Dentro de los cambios más notorios, se destaca que, en las últimas ediciones, incorpora una sección introductoria de ocho capítulos sobre el progreso económico, la naturaleza de la disciplina, su utilidad y la relación con la moral y con otras ciencias; en la sección de producción, se reubicó el capítulo sobre la riqueza, para ubicarlo en primer lugar, para destacar su importancia; además, se incorporaron capítulos sobre oferta y demanda, propiedad, agentes naturales, industria extractiva, propiedad territorial, fabricación por cuenta del Estado, sistema protector, aduanas,

${ }^{17}$ Se cita aquí la versión de 1870, por ser la que utilizaba Manuel Ancízar. 
balanza de comercio, sistema colonial español, compañías privilegiadas de comercio y emigraciones. En la parte correspondiente a la circulación, se adicionaron capítulos sobre extracción de moneda, alteración de la moneda y cajas de ahorro y montes de piedad. En la parte de distribución, se agregó un capítulo sobre libertad de concurrencia. Por último, en la parte dedicada al consumo, se añadió un capítulo sobre el ahorro y la disipación.

Colmeiro señala en el libro dos condiciones fundamentales del progreso de la industria: el primero es el desarrollo de las ciencias, que permite descubrir las leyes de la naturaleza y enseña al hombre el modo de aplicarlas a la producción; de allí la importancia del estudio de las Ciencias exactas, físicas y naturales; y el segundo, el perfeccionamiento de las artes industriales, que consiste en los conocimientos adquiridos y transmitidos a través del tiempo; de allí la importancia de los conocimientos prácticos.

Al igual que Smith y Say, Colmeiro considera que un requisito de la generación de riqueza es la existencia de un gobierno estable y admite la existencia de intereses más poderosos que los materiales, fuera de los límites de la Economía política. Distingue a la Economía política de la moral, la justicia, la política, la estadística y la administración.

El texto que Ancízar seleccionó como texto complementario para su curso es de autoría de Joseph Garnier (1868), ${ }^{18}$ un seguidor de Say, e igual que con los libros ya referenciados, se trata de un manual que tiene como objetivo enseñar los principios de la Economía política. La influencia de Say se aprecia, por ejemplo, en la concepción de utilidad; Garnier, al igual que Say, considera que la utilidad de un bien o servicio no se puede medir directamente con objetividad, pues la utilidad solo se reconoce una vez que la necesidad se ha satisfecho; en la satisfacción de la necesidad a través del consumo se valoran los bienes y ese valor es la medida indirecta de la utilidad. Entonces, la utilidad aparece como algo intrínseco a los objetos; es algo que preexiste en los objetos o que se puso en ellos a través del trabajo humano. Luego, en estas teorías, aun no resulta dominante la teoría subjetiva del valor, ni las nociones de utilidad marginal y el principio de la utilidad marginal decreciente; tampoco la escasez como problema económico fundamental, temas propios del enfoque marginalista que, en la segunda mitad del siglo XIX, avanza para convertirse en paradigma dominante de la Economía.

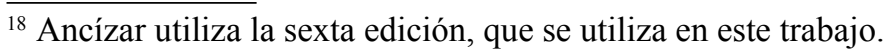


El libro de Garnier es una respuesta al auge del proteccionismo y del socialismo, doctrinas que considera erróneas, pero ganan popularidad entre sus contemporáneos, lo que resta importancia a lo que él consideraba los principios científicos de la Economía política clásica; por ello, propuso fortalecer la Economía política mediante el uso de Estadística, que puede aprovechar las observaciones de la historia y la geografía, para utilizarlas como guía de la administración de los Estados (Garnier, 1868, p. XV).

En el programa de Economía política de 1873, Ancízar estructuró el curso a partir de un conjunto de proposiciones agrupadas en secciones, que corresponden al mismo orden que había propuesto Colmeiro; es decir, luego de unas reflexiones preliminares, se divide el estudio de la Economía en los procesos de producción, distribución, circulación y consumo, aunque el programa de Ancízar tiene la particularidad de extraer de la circulación los temas de cambio, crédito, bancos y vías de comunicación, para asignarles apartados independientes, lo que puede indicar la relevancia que pretendía otorgarle a estos temas. Las disertaciones, con que se evaluó a los estudiantes de Ancízar, prueba presentada al finalizar el año escolar, constituyen otra fuente para intuir la importancia relativa otorgada a algunos temas dentro del espacio académico. Los estudiantes disertaron sobre: principios generales; producción en general y factores de producción; el trabajo como factor de producción; circulación y cambio de la riqueza; teoría de la población; consumos privados; y consumos públicos y fiscalidad (Ancízar, 1873b).

En el primer apartado del programa, se presentan unas nociones preliminares; la primera de ellas señala que la naturaleza humana se compone de tres dimensiones: física, moral e intelectual, que determinan, respectivamente, necesidades de existencia, de justicia y de ciencia. En este punto, parece seguir a Garnier, pues Colmeiro solo destaca las dimensiones física y moral; el autor francés considera que el hombre vive en sociedad y tiene una triple naturaleza: moral, intelectual y física (Garnier, 1868, p. 4 y 660). Estas necesidades las presentaba Ancízar como un estímulo, que obliga al ser humano a desarrollar el ingenio que le permitiera procurarse los medios de satisfacer sus necesidades.

Las necesidades son el primero de dos móviles de la acción humana que plantea Ancízar (1873a, p. 99); el segundo es el interés individual (1873a, p. 101); aquellas son un "estímulo" y este la "guía", que permiten el desarrollo de las facultades humanas para procurarse los medios de satisfacer las necesidades. Esto concuerda con el planteamiento de 
Garnier (1868): "La necesidad y el interés individual son estímulos del esfuerzo, del trabajo, de la invención, de la previsión, del ahorro y de la propiedad" (p. 14).

El trabajo lo define Ancízar como ejercicio de las "facultades" aplicadas a la modificación útil del entorno, lo que, considerado en términos agregados, constituye la industria. Así, la producción es resultado de combinar materias primas con las fuerzas físicas y las "aptitudes personales"19 para satisfacer necesidades. El producto de la industria constituye la riqueza, que puede ser de naturaleza material o inmaterial, pues su fin es satisfacer necesidades de distinto orden.

Ancízar atribuye gran importancia a la propiedad en el desarrollo de la civilización; la define como "la posesión exclusiva y la libre disposición de la Riqueza" y la considera "condición esencial del desarrollo de la industria y fundamento de las sociedades civilizadas" (1873a, p. 99), lo que Garnier (1868) expresa como: "La posesión y el disfrute exclusivos de esta riqueza, ya sea producida o natural, constituyen el derecho de propiedad, reconocido y garantizado por la sociedad, y tanto más garantizado y protegido como la civilización está más avanzada" (p. 13). Ancízar considera que la seguridad de la propiedad es condición esencial de la prosperidad (1873a, p. 104); según Garnier, el "derecho de propiedad es la piedra angular de la estructura social" (1868, p. 13).

En cuanto a los asertos relacionados con el valor y los precios, se destaca que Ancízar define a la utilidad en función de la adecuación de las cosas a la satisfacción de las necesidades; y al valor como un derivado de la utilidad, una estimación de equivalencia entre bienes en el momento de realizar un intercambio o permuta, lo que implica la transmisibilidad de la propiedad. Así, utilidad y valor son cualidades relativas, que se concretan en el uso, en la satisfacción de las necesidades. La expresión monetaria del valor es el precio, que se determina por la relación momentánea entre oferta y demanda, que Ancízar denomina "petición", ${ }^{20}$ combinada con "la competencia (o concurrencia) entre los que piden y los que ofrecen

${ }^{19}$ Por "aptitudes", Ancízar parece referirse a las dimensiones morales e intelectuales; y por "facultades", como lo plantea luego, en la sección de producción, incluye, además de las anteriores, a las fuerzas físicas.

${ }^{20}$ Propio de las traducciones al castellano de obras francesas fue traducir la expresión l'offre et la demande, utilizada, por caso, en el libro de Garnier (1868), cuya edición francesa estaba utilizando Ancízar en el curso, como "la oferta y el pedido", pues esta última expresión era la más común en el lenguaje al uso. 
productos" (Ancízar, 1873a, p. 99). El precio necesario cubre estrictamente los gastos de producción y el precio corriente lo supera. En general, estas proposiciones se encuadran dentro de la tradición de Say, quien, en este punto, se distancia de la teoría del valor-trabajo de Adam Smith, para proponer una teoría basada en los costos de producción y la utilidad, es decir, en las nociones de oferta y demanda.

El análisis de la oferta y la demanda, el proceso de formación de precios y la explicación del fenómeno de la concurrencia, temas fundamentalmente teóricos, se encuentran desarrollados en los libros de Colmeiro y de Garnier; sin embargo, Ancízar aparentemente no los desarrolla en profundidad en el curso.

Ancízar termina las nociones preliminares con una definición de la Economía política:

ECONOMÍA POLÍTICA es la ciencia que demuestra y explica las leyes naturales reguladoras de la industria.

O también: la ciencia que demuestra y explica las leyes que determinan el modo más natural (y por tanto más acertado) de producir, distribuir, circular, cambiar y consumir la Riqueza producida (Ancízar, 1873a, p. 99-100).

En las proposiciones sobre la producción, se destaca la importancia otorgada al trabajo humano. Primero, se enuncian los factores productivos: trabajo, instrumentos y capital. El trabajo se asocia al ejercicio de las "facultades o ingenio" de sabios, empresarios y obreros. El sabio se encarga de crear inventos y vulgarizar la ciencia; el empresario de aplicar la ciencia y el trabajo a la extracción de materias primas, al cultivo, al transporte, a la manufactura y al comercio; y el obrero solo es un agente ejecutor de órdenes. Los instrumentos se componen de tierra o suelo cultivable; recursos comunes, como mar, ríos, calor y luz solares y la atmósfera, que Ancízar asocia a las fuerzas químicas, mecánicas y físicas; e instrumentos apropiados; por ejemplo, corrientes de agua utilizadas y máquinas.

Trabajos e instrumentos son factores primitivos, de los cuales se deriva el tercer factor: el capital, que puede ser material o inmaterial. Dentro del capital material se encuentran provisiones, semillas, materias primas, máquinas, edificios, animales de labor y moneda; y dentro del capital inmaterial están los conocimientos, el ingenio y la moralidad. Ancízar aclara la relación del capital con el consumo y el ahorro y su dimensión intertemporal, cuando define el capital como: 
«cúmulo de productos (Valores, Riqueza) sustraídos al Consumo directo, y aplicados como factor (instrumento auxiliar) a la Producción de la Riqueza futura.» Para que un cúmulo de productos (Riqueza) sea Capital, es necesario que se emplee en la Producción futura: si está inactivo y guardado, es Riqueza estacionaria: si se aplica directamente a la satisfacción de necesidades, es Riqueza de consumo. (Ancízar, 1873a, p. 100).

En el programa, se presenta al trabajo como el factor productivo fundamental, del cual se derivan los demás: "el factor único de la Producción es el hombre, mediante el empleo de sus facultades físicas, morales e intelectuales en la modificación útil de las cosas y del hombre mismo" (1873a, p. 100); en particular, con trabajo se produce tierra útil y capital. El trabajo humano define el campo económico: "todos los hechos económicos no son más que manifestación del ingenio del hombre en lucha con sus necesidades" (1873a, p. 100), al punto que "la Economía política no es, en el fondo, sino una rama de la Antropología, reducida al estudio del hombre como animal industrioso" (1873a, p. 101).

El capital es un factor auxiliar de la producción; debido a él, se facilita, aumenta, perfecciona y abarata la producción; es resultado de la previsión y el ahorro y requiere seguridad; Ancízar la llama "seguridad social", para garantizar una provisión suficiente. Las máquinas abaratan los productos, facilitan el trabajo de los obreros y mejoran su remuneración (Ancízar, 1873a, p. 101). En el caso de la tierra, que en su estado natural poco ofrece de útil al hombre, combinada con el trabajo humano, "puede considerarse como una máquina, obra del hombre. De aquí la legitimidad de la propiedad y de la Renta territoriales" (Ancízar, 1873a, p. 101).

La división del trabajo, la separación de ocupaciones o tareas, "aumenta y perfecciona la producción", permite ubicar la mano de obra en la ocupación preferida y más fácil, ahorra tiempo en el desempeño de las actividades y motiva y ocasiona los inventos (Ancízar, 1873a, p. 101). Sin embargo, presenta límites, producto de la naturaleza de la industria, la clase de producción y la extensión del consumo de sus productos.

Por último, Ancízar plantea que el trabajo y la producción no necesitan más guía que el interés individual, de lo cual extrae un corolario: "Cualquiera intervención de los gobiernos en el modo de la producción es perjudicial" (1873a, p. 101).

La distribución se define, en el programa, como reparto inmediato $\mathrm{y}$ anticipado del valor de los productos entre los que han concurrido a 
formarlos. Las remuneraciones a los factores productivos se presentan como precios, por su uso en el proceso de producción. Así, la renta es el precio del uso de la tierra ya utilizada y de los edificios, y Ancízar aclara que: "La Renta es efecto, no causa, del Precio de los productos agrícolas" (Ancízar, 1873a, p. 101); el salario es precio del trabajo humano; se puede expresar en términos reales y nominales y su nivel depende de la relación entre capital y población obrera y de la naturaleza del servicio del obrero. El trabajo intelectual es mejor remunerado que el trabajo físico y el interés es el precio del uso del capital mueble y depende de la relación entre la oferta y el "pedido de capitales" y de la solidez o flaqueza del crédito.

La suma completa de rentas, salarios e intereses equivale a los gastos de producción. Las remuneraciones a los factores productivos se tratan como anticipos del capital, las paga el empresario antes de llevar sus productos al mercado; su reembolso depende del consumo; es decir, de la demanda. El precio de los productos que garantiza el reembolso es el precio necesario; si no se alcanza, se anula la producción. El corolario que Ancízar deduce de considerar que las remuneraciones son precios y, en consecuencia, los establece el mercado, es que todo intento de intervención del gobierno, cuando pretende fijar las remuneraciones, es ineficaz.

En el programa de Ancízar, se analiza la circulación en términos genéricos y, luego, se desglosan los temas de cambio, crédito, bancos y vías de comunicación. La circulación consiste en el "transporte de la Riqueza desde el lugar en que es producida, hasta aquel en que se ofrece al Consumo, sea momentáneo (industrial) sea definitivo" (1873a, p. 102). Se establece que la base de la circulación son los mares, ríos, canales y caminos; es decir, los medios de comunicación, que permiten acercar los productos al consumidor; su desarrollo permite aumentar la utilidad de los productos y la actividad comercial. Incluso:

Es el lazo que une todas las ramas de la Industria, proveyéndolas de materiales, de instrumentos y aún de obreros.

La Circulación relaciona los pueblos, difunde la civilización, ensancha la sociedad económica más allá de los límites de la sociedad política, y desvanece las preocupaciones y las malquerencias internacionales (Ancízar, 1873a, p. 102).

Ancízar define el cambio como acto de permuta de un producto o servicio por otro que se juzga como equivalente: "nace de la división del trabajo, y es consecuencia necesaria del estado de sociedad" (1873a, p. 
102); su extensión y variedad dependen de la intervención de la moneda, que se define como "el instrumento intermediario y facilitador de los cambios, siendo ella misma equivalente a los valores porque se cambia, y sirviéndoles de común denominador" (1873a, p. 103). Ancízar aclara que la moneda, además de ser medio de cambio, puede "consumirse como los demás productos, y de tener Precio, regulado por la ley común a todo precio" (1873a, p. 103), y aclara que "La Moneda por sí sola puede formar la Riqueza de un individuo, pero no la de una Nación" (1873a, p. 103).

El consumo implica la "destrucción momentánea o definitiva de valores; puede ser reproductivo, no-reproductivo, o improductivo" (Ancízar, 1873a, p. 103). El consumo reproductivo o industrial tiene lugar en el acto de producción; el consumo no-reproductivo implica la destrucción definitiva del valor de los productos utilizados para la conservación y comodidad de la existencia humana; y en el consumo improductivo se destruye valor sin generar ningún resultado industrial ni satisfacer ninguna necesidad personal o social.

El consumo puede ser privado, cuando lo efectúan los individuos para satisfacer sus necesidades personales o para realizar una actividad productiva, o público, cuando lo establecen los gobiernos para satisfacer necesidades sociales. En este caso, su financiación depende de las contribuciones, de los impuestos, ya fueran directos o indirectos, respecto a lo cual se plantea que:

Científicamente hablando, contribuir es comprar seguridad. Hay expoliación siempre que no se devuelve en servicios de seguridad y comodidad lo que se toma como Contribución.

Las contribuciones deben ser proporcionadas a la fortuna (Riqueza) de cada contribuyente, y tener por base la Renta. (Ancízar, 1873a, p. 103).

Además, se mencionan los principios clásicos de la tributación; es decir, que la cuota de la contribución debe ser cierta y determinada en cuanto a la cantidad, el tiempo y el modo de pagar. La sección termina por plantear el tema de los empréstitos públicos, los asuntos de cuándo y cómo contratarlos y sobre sus ventajas e inconvenientes, con la indicación respecto a que su evaluación depende de la naturaleza de los consumos públicos que el crédito permite.

Las dos secciones finales del programa tratan del crédito y los bancos; el primero permite convertir el ahorro, que Ancízar denomina 
riqueza estacionaria, en capital, o producción de riqueza futura, y enfatiza en la importancia de la confianza entre prestamista y prestatario en el funcionamiento del sistema, que valora positivamente, tanto por permitir el traslado de recursos de las manos ociosas hacia manos productivas como por estrechar los vínculos sociales entre individuos y entre naciones. En el caso de los bancos, se definen como oficinas que cumplen la función de facilitar las operaciones de crédito; se establece la distinción entre bancos de depósito y bancos de circulación; se plantea la necesidad de estudiar sus características, funcionamiento y ventajas. Por último, se plantean las dificultades para establecer bancos agrícolas y los efectos económicos de la emisión (Ancízar, 1873a, p. 104). Estos temas resultan pertinentes para los contemporáneos; en Colombia, en la década de los años setenta del siglo XIX, está empezando una experiencia de banca libre, con la formalización de la actividad bancaria, como es el caso de la fundación del Banco de Bogotá, en 1870, el Banco de Antioquia y el Banco de Santander, en 1872, y el Banco de Barranquilla, en 1873; este es un sistema basado en la confianza por parte del público, pues de ella depende la participación en el mercado monetario de cada entidad Rodríguez Salazar, 2016, p. 69-77).

El programa finaliza con un planteamiento sobre la importancia de las vías de comunicación en la producción y circulación de riqueza, su importancia en la determinación de los costos de la producción y los niveles de consumo, y con una conclusión sobre las condiciones favorables al progreso económico:

Las condiciones favorables a la prosperidad de todas y cada una de las ramas de la Industria se pueden resumir en dos palabras:

SEGURIDAD y LIBERTAD.

La libertad de la Industria y la seguridad de la Propiedad dejan venir y realizarse la Concurrencia, reguladora y armonizadora de todos los intereses. (Ancízar, 1873a, p. 104).

\section{Discusión}

A Grosso modo, la Economía política, tal como se concebía en la época de Manuel Ancízar, era el estudio del origen de la riqueza y de su distribución; sin embargo, según este profesor, la Economía no debía recibir un tratamiento reduccionista. Por contra, veía el desempeño económico entrelazado con otros fenómenos, tales como el progreso material y, en 
general, el desarrollo social. Evidentemente, los resultados de la Economía política, tales como la concepción del trabajo en tanto creador de riqueza, la participación del capital, la tenencia de tierra y las condiciones del mercado en su distribución, incidían en diferentes aspectos de la vida social; por ejemplo, en la forma de la distribución de la riqueza, la reducción o agudización de la pobreza, el descontento social o la exacerbación de las diferencias de clase, todo lo cual era objeto del pensamiento social. Así las cosas, según Ancízar, los fenómenos económicos se entrelazaban con los hechos sociales; por ejemplo, al reflejarse las formas de producción $\mathrm{y}$ distribución en una estructura de clases y en determinado tipo de apropiación social de la riqueza. En suma, los efectos de los fenómenos económicos en el comportamiento de la sociedad constituían tópicos del pensamiento social.

De conformidad con su concepción de la Economía, según la cual los fenómenos económicos se entrelazaban con otros fenómenos sociales, Ancízar considera relevante utilizar los textos de Manuel Colmeiro (1842) y Joseph Garnier (1868), habida cuenta el hecho de que proveían el material fundamental para la formación de profesionales que habían de formular conceptualizaciones sobre Economía; es decir, referentes a la gestión pública, a asuntos relacionados con regulación o política económica, tal cual era el caso de los abogados y juristas que se estaban formando en la Universidad. En consideración de Ancízar, el material de los referidos autores era pertinente por cuanto el correspondiente a Colmeiro tenía un enfoque ecléctico, en el sentido de que los Principios de Economía Política (1842) subrayan la importancia de la observación y la experiencia, por oposición al excesivo raciocinio de las fuentes clásicas, amén del dogmatismo filosófico de la misma Escuela Clásica. El texto de Garnier, por su parte, al enseñar los principios de la Economía política según la concepción de J. B. Say, era un manual pertinente por cuanto Ancízar consideraba central no desligar la economía de la moral. Por esto, los textos utilizados constituían un material apropiado para enseñar los aspectos más pertinentes de la teoría económica, tanto por el contenido como por el método.

Ahora bien, el material elegido suministraba los elementos básicos para que los profesionales en formación, en este caso abogados, pudieran tener una comprensión apropiada de los fenómenos económicos, de tal suerte que su contribución a los asuntos que se les consultaran y/o que tuvieran que tratar, se realizara de la mejor manera posible; por ejemplo, 
para conceptualizar o asesorar en temas referentes a la elaboración de políticas públicas de planificación en asuntos de vías de comunicación, planes de gobierno o apoyo a los partidos políticos, entre otros. En general, el material utilizado procuraba abarcar la temática básica. Por lo demás, se buscaba que el profesional tuviera muy claro que el trabajo era el motor de progreso y bienestar, social e individual, como, también, el papel que tenía el capital -en todas sus formas, lo que incluía el capital humano- y la tierra en el continuo mejoramiento del bienestar. Sin embargo, acerca de los eventuales conflictos que se produjeran por la distribución social de la riqueza, vale decir problemas de justicia distributiva, el material utilizado no suministraba elementos significativos tanto para entender la forma de tratarlos adecuadamente, como tampoco para solucionarlos. La teoría de la distribución se restringía a señalar que la riqueza se distribuía en forma de salarios, tasas de interés, beneficios y rentas, de conformidad con los cánones de la Escuela Clásica.

Por su parte, el material consultado para valorar la contribución del profesor Ancízar a la enseñanza de la Economía, muestra cómo lo elegido para estructurar e impartir los cursos de Economía política respondía de forma pertinente y oportuna a los problemas de Economía de su época. Es claro, los textos seguidos procuraban enseñar lo básico, en el sentido de mostrar los elementos cruciales para el entendimiento de la Economía, en particular el papel especial y preponderante del trabajo en la generación de riqueza. De ahí que se consideraba que los futuros profesionales tomarían en cuenta este hecho y que, consecuentemente, propugnarían por la generación de empleo como medida decisiva dentro de la formulación de intervenciones públicas. Así las cosas, de conformidad con los postulados de la Economía política y el papel trascendental del trabajo en la creación de riqueza, y en su distribución, asuntos referentes a la carencia de ingresos, la pobreza, la inexorable industrialización y el correspondiente debilitamiento del sector artesanal, la progresiva forma de contratación de trabajo asalariado y la concomitante dependencia del jefe capitalista, entre otros, constituían temas ineludibles, no solo para los economistas, sino, también, para el pensamiento social.

Evidentemente, la valoración de la contribución de Ancízar en la enseñanza de la Economía se establece al tomar en cuenta el contexto social e histórico de la época correspondiente, la década de los años setenta del siglo XIX. A la sazón, el país estaba bajo un régimen de organización 
política y administrativa federal y bajo la dirección de los denominados Radicales. El país se hallaba inmerso en conflictos de diversos órdenes, dentro de los cuales descollaba el asunto de la dirección y orientación de la política educativa; puntualmente, el tema a dirimir era si debía regirse con parámetros y principios católicos o si debía ser laica, sobremanera la educación pública, en particular, porque, en un país con la magnitud y profundidad de la pobreza que se tenía, dejar la enseñanza "en manos del interés privado era cerrar el camino para que los sectores pobres de la sociedad pudiesen acceder a ella, y por esto mismo se les cerraba el camino a la administración pública, a la tribuna y a la prensa" (Cortés Guerrero, 2006, p. 328).

El momento en el que se creaba la Universidad, el proyecto educativo de la administración de turno -los Radicales- se orientaba a promover el desarrollo significativo y efectivo del país, en razón de lo cual se consideró el establecimiento de una institución que formara técnicos y científicos para su desarrollo. Por lo demás, en su concepción, se consideró que la educación allí impartida debía ser a-confesional. Al respecto, se señala que este solo hecho bastó para originar un largo y enconado debate acerca de si la educación de la Universidad debía ser laica o confesional, como quiera que su financiación dependía de recursos públicos y que el país era perentoriamente católico. Más aun, el señalado debate se agudizó habida cuenta la obligación de incluir los textos de Jeremy Bentham y Destutt de Tracy (junio de 1870), en los planes de estudio. Este era el contexto institucional (un país concluyentemente católico) y coyuntural (la reciente obligatoriedad de seguir unos textos de Bentham y Tracy), en el momento en el que Ancízar se desempeñaba como primer rector de la Universidad, cuya respuesta personal a la obligatoriedad de seguir textos y, en general, tener que consentir la intromisión del Estado en asuntos de la educación, fue la renuncia a la rectoría de la recién constituida Alma Mater.

Como tal, se debe considerar que el contexto institucional y la misma coyuntura aludida ofrecen una muestra representativa de la forma como se estaban realizando los diversos ajustes institucionales. De un lado, el hecho de que se obligara a seguir determinados textos en la educación constituía una verdadera extralimitación por parte del Estado, en particular por parte del grupo en el poder, no solo porque esa medida iba en contravía de los mismos mandatos que se habían acordado bajo el régimen Radical (el de la libertad de culto); de otro lado, porque no atendía el hecho de 
que la población colombiana era decididamente católica. Sin duda, esta situación representa uno de los ejemplos proverbialmente verificados en la Historia colombiana, según el cual se pretende modificar el orden existente a base de leyes, en este caso mediante la implantación de mandatos que no corresponden al "espíritu del país". Al respecto, puede considerarse que, si bien un hecho puede corresponder a medidas que se instauren tendientes a modificar la institucionalidad, otro muy diferente es instaurar medidas que van en contravía del "espíritu de la nación", más aún cuando se introducen de forma abrupta, vale decir las que se establecen contra de los hábitos y valores, entre otros. De nuevo, el asunto no solo es que se pretende modificar la realidad o el contexto institucional, muy posiblemente con las mejores intenciones, a base de leyes, sino, también, se intenta sin tener en cuenta los intereses de todos los afectados, es decir, las modificaciones se incluyen por "encima de los conciudadanos", sin consultar el citado "bien general". De ahí el tipo y magnitud de reacciones, amén de los mismos resultados de las modificaciones de marras; en realidad, el tema es más complejo de lo que los dirigentes y diferentes sectores sociales usualmente consideran. Al respecto, metafóricamente, se puede considerar a "la sociedad [como...] un organismo complejo cuyo equilibrio depende de la gradual adaptación de las medidas políticas a los nuevos hechos sociales. No todo puede depender de la ley" (Colmenares, 1997, p. XVII).

\section{Conclusiones}

Manuel Ancízar fue una de las figuras intelectuales y políticas más destacadas del siglo XIX en Colombia; son muchos sus aportes en los distintos campos en que se desempeñó; aquí destacamos su legado en la promoción de procesos de sociabilidad académica, la promoción de conocimientos útiles y la organización de la Universidad Nacional, en su primera época; la atención se centra en sus aportes a la enseñanza de la Economía política durante el siglo XIX. Ancízar asumió el reto de formar profesionales idóneos, capaces de aplicar sus conocimientos a los problemas del país, en un contexto económico caracterizado por reformas liberales y auges efímeros de los procesos de agroexportación, que permitieron dinamizar la actividad productiva, el trabajo, el transporte y el comercio, pero que no se tradujo en reinversión de capitales, mejoras de la industria y de las técnicas agrícolas y calificación de la mano de obra. 
La Economía política ofrece una fuente de inspiración teórica, de herramientas conceptuales y de criterios normativos que ayudan a entender el orden social e influyen en la forma de interpretar y tratar de intervenir sobre condiciones concretas y problemas prácticos. Los énfasis temáticos del programa, los libros de texto que propone para orientar el curso y las disertaciones de los estudiantes ofrecen luces sobre el pensamiento económico de Ancízar y sobre los problemas que captaban su atención. En este sentido, Ancízar plasmó en su programa de la asignatura la idea según la cual la mejor forma de funcionamiento de la Economía se produce cuando sigue su curso espontáneo, cuando el sistema económico opera conforme a leyes naturales, lo que da por sentado que la concurrencia se encarga de regular y armonizar los intereses de la sociedad, para lo cual se requiere proporcionar condiciones de seguridad a la propiedad y libertad de empresa.

La mayoría de los temas en que enfatiza Ancízar ya habían sido objeto de su interés en los distintos ámbitos de desempeño, en su larga trayectoria como hombre público, y resultaban pertinentes en la coyuntura colombiana del momento. De esos temas, se destaca su convicción en la necesidad de potenciar las facultades productivas del trabajo, por ser la fuente de la riqueza, la necesidad de mejorar las condiciones de circulación de la producción, lo que implica mejorar la infraestructura de transportes y comunicaciones, que permitieran ampliar los circuitos mercantiles y difundir la civilización. También, concedió importancia al ingenio y la asunción de riesgos por parte de los empresarios, la teoría de la población, el crédito, los bancos y la fiscalidad.

En el programa de Economía política, Ancízar parece estar más influido y seguir el libro de Garnier (1868) que el de Colmeiro (1859/1870); es decir, predomina el texto de consulta por sobre el libro guía, lo que permite dejar planteada la hipótesis de que, en la selección de textos, se impuso el criterio de mayor simplicidad del libro de Colmeiro y las ventajas que un libro en castellano podría tener para los estudiantes. Por último, otro aspecto que vale la pena dejar planteado es la coincidencia de los autores, Ancízar, Garnier y Colmeiro, en seguir la tradición de no desligar la Economía de la moral, un elemento importante en la obra de Say, al destacar las cualidades morales del ser humano, al que se atribuye una triple naturaleza: moral, intelectual y física; así, por ejemplo, del empresario se espera buen juicio, constancia y buen entendimiento de las personas (Garnier, 1868, p. 4 y 
660), aunque estos autores están de acuerdo en que los atributos morales no suplen la insuficiencia de factores productivos; además, están de acuerdo en que el desarrollo económico requiere de la confianza mutua para favorecer las relaciones de intercambio entre agentes económicos y que, de alguna manera, existe una tensión entre el incremento de la riqueza y los atributos morales, y estos se tratan como un recurso escaso que se debe preservar.

\section{Referencias}

Ancízar, Manuel. Peregrinación de Alpha (M. Ancízar). Por las Provincias del Norte de la Nueva Granada en 1850 i 51. Bogotá: Imprenta de Echavarria Hermanos, 1853.

Ancízar, Manuel. "Renuncia". Anales de la Universidad Nacional de los Estados Unidos de Colombia. Vol. 3. No. 18, (1870): 505-507.

Ancízar, Manuel. "Programa economía política". Anales de la Universidad Nacional de los Estados Unidos de Colombia. Vol. 7. No. 51, (1873a): 99105, https://revistas.unal.edu.co/index.php/analesun/article/ view/13081

Ancízar, Manuel. "Disertaciones en las clases de Derecho Internacional y Economía política". Anales de la Universidad Nacional de los Estados Unidos de Colombia. Vol.7. No. 58 (1873b): 438-439, https://revistas.unal. edu.co/index.php/analesun/article/view/13184

Arévalo Hernández, Decsi Astrid. "Sobre un manual de libre cambio". En Economía Política y Estadística. Lecciones dictadas en la Universidad Nacional por el doctor Santiago Pérez, de Pérez Manosalva, Santiago. Bogotá: Universidad Externado de Colombia, 2002. 23-53.

Chaparro, Germán y Gallardo, Álvaro. "El pensamiento económico de los primeros economistas colombianos”. Lecturas de Economía. No. 83 (2015): 229-253.

Colmeiro, Manuel. "Introducción". En Economía Política ó Principios de la Ciencia de las Riquezas, de Droz, Joseph. Madrid: Libreria de los Señores Viuda de Calleja é Hijos, Imp. de A. R. Calleja, 1842. III-XXXIV.

Colmeiro, Manuel. Tratado Elemental de Economía Política Ecléctica. Madrid: Librería de los señores viuda e hijos de Antonio Calleja, 1845. 
Colmeiro, Manuel. Principios de Economía Política. Madrid: Imprenta de F. Martínez García, 1859/1870, http://biblioteca.galiciana.gal/es/consulta/ registro.do? $\mathrm{id}=4749$

Colmenares, Germán. Partidos Políticos y Clases Sociales. Bogotá: Tercer Mundo, 1997.

Correa Restrepo, Juan Santiago. "Introducción”. En Economía Política y Estadística. Lecciones dictadas en la Universidad Nacional por el doctor Santiago Pérez, de Pérez Manosalva, Santiago Bogotá: Universidad Externado de Colombia, 2002. 11-22.

Cortés Guerrero, José David. "Los debates político-religiosos en torno a la fundación de la Universidad Nacional de Colombia, 1867-1876". En El Radicalismo Colombiano del Siglo XIX, editado por Sierra Mejía, Rubén. Bogotá: Universidad Nacional de Colombia, 2006. 327-349.

Del Castillo, Lina. La Invención Republicana del Legado Colonial: Ciencia, Historia y Geografía de la Vanguardia Política Colombiana en el Siglo XIX. (M. J. Montoya Durán, Trad.) Bogotá: Universidad de los Andes y Banco de la República de Colombia, 2018.

Droz, Joseph. Oeuvres de Joseph Droz: III. Économie Politique ou Principes del la Science des Richesses. París: Jules Renouard, 1829.

Garnier, Joseph. "Traité d'économie politique sociale ou industrielle: exposé didactique des principes et des applications de cette science et de l'organisation économique de la société" (sexta ed.). París: Garnier Frères, 1868.

Hurtado, Jimena. "La economía política los estudios superiores en la segunda mitad del siglo XIX en Colombia. Ezequiel Rojas, sus influencias y programas". En Ideas y Políticas Económicas en Colombia Durante el Primer Siglo Republicano, editado por Álvarez, Andrés y Correa, Juan Santiago. Bogotá: Ediciones Uniandes, 2016. 35-67.

Jaramillo Uribe, Jaime. El pensamiento colombiano en el siglo XIX. Bogotá: Alfaomega, 2001.

Kalmanovitz, Salomón. "Notas para una historia de las teorías económicas en Colombia". En Historia Social de la Ciencia. Tomo IX: Ciencias Sociales, editado por Vasco, Carlos Eduardo, Obregón, Diana y Orozco, Luis 
Enrique. Bogotá: Instituto colombiano para el desarrollo de las ciencias y la tecnología Francisco José de Caldas, Colciencias, 1993. 13-61.

Loaiza Cano, Gilberto. Manuel Ancízar y su Época (1811-1882). Biografía de un Político Hispanoamericano del Siglo XIX. Medellín: Editorial Universidad de Antioquia, 2004.

López Domínguez, Luis Horacio, ed. Obra Educativa: La Querella Benthamista, 1748-1832. Bogotá: Fundación Francisco de Paula Santander, 1993.

Madrazo, Pedro de. "Prólogo del traductor". En Curso de Economía Política, de Rossi, Pellegrino. Madrid, España: Boix, 1840. V-XXXII.

Mayor, Alberto y Tejeiro, Clemencia. "La profesión de economista en Colombia: Entre el autodidactismo y el entrenamiento académico". En Cambio Técnico, Empleo y Trabajo en Colombia. Aportes a los Estudios Laborales en el VIII Congreso de Sociología, editado por Dombois, Rainer y López, Carmen Marina. Bogotá, Colombia: Fundación Friedrich Ebert de Colombia, FESCOL, 1993. 199-222.

Otero Muñoz, Gustavo. “Don Manuel Ancízar”. En Editoriales del Neo-Granadino, de Ancízar, Manuel (3ª ed). Bogotá: Minerva, 1940. 5-17.

Peiró Martín, Ignacio y Pasamar Alzuria, Gonzalo. "Colmeiro y Penido, Manuel". En Diccionario Akal de Historiadores Españoles Contemporáneos, editado por Peiró Martín, Ignacio y Pasamar Alzuria, Gonzalo. Madrid, España: Ediciones Akal, 2002. 195-197.

Pérez Manosalva, Santiago. Economía Política y Estadística. Lecciones dictadas en la Universidad Nacional por el doctor Santiago Pérez, editado por Correa Restrepo, Juan Santiago. Bogotá: Universidad Externado de Colombia, 2002.

Presidencia de la Nueva Granada. Decreto de creación de un instituto que fomente el desarrollo de la inteligencia, la conservación de la moral y el perfeccionamiento de la industria en el pueblo granadino. (22 de diciembre de 1847). En Codificación Nacional de 1928. Tomo XII, editado por Correa, Ramón, https://babel.hathitrust.org/cgi/ pt?id=uc1.\$b507208\&view=1up\&seq=7. 481-486.

Restrepo, José Manuel. "Educación Pública. Circular. República de Colombia. - Ministerio de Estado en el Departamento del Interior. Sección Segunda 
(20 de octubre de 1828)". Gaceta de Colombia. No. 382. (3 de octubre de 1828). En De la Perplejidad a la Explicación: Crónicas de la Economía, su Enseñanza y Aplicación, de Rhenals Monterrosa, Remberto. Medellín: Universidad de Antioquia, 2003.

Rivera, Magda. "Institucionalización de los estudios económicos en la Universidad Nacional de Colombia, 1945-1952”. En Búsquedas y logros desde la academia, editado por Hernández Gamarra, Antonio y Herrera Valencia, Beethoven. Bogotá: Universidad Nacional de Colombia, 2002. 22-50.

Rodríguez Salazar, Oscar. "El pensamiento económico en la formación del estado granadino: 1780-1830 (Primera parte)”. Historia Crítica. No. 1, (1989): 93110 .

Rodríguez Salazar, Oscar. "El pensamiento económico en la formación del estado granadino: 1780-1830 (Segunda parte)". Historia Crítica. No. 2, (1990): 107-117.

Rodríguez Salazar, Oscar. "Soberanía y moneda en el siglo XIX en Colombia". En Soberanía política y regímenes monetarios, editado por Arévalo Hernández, Decsi. Bogotá, Colombia: Universidad Nacional de Colombia, 2016. 21124.

Rodríguez Salazar, Oscar y Arévalo Hernández, Decsi. (1994). "La historiografía económica colombiana del siglo XIX". En La historia al final del milenio: Ensayos de historiografía colombiana y latinoamericana, compilado por Tovar Zambrano, Bernardo. Bogotá, Colombia: Universidad Nacional de Colombia, 1994. 187-250.

Rojas, Ezequiel. Programa para la enseñanza de la economía política en las universidades de la República, formado por el Dr. Ezequiel Rojas y aprobado por la Dirección General de Instrucción Pública. Bogotá: Biblioteca Nacional de Colombia, Fondo Pineda, folio 39, pieza 9, 1844.

Rojas, E. "Programa para la enseñanza de la economía social, formado por el rofesor doctor Ezequiel Rojas". Anales de la Universidad Nacional de los Estados Unidos de Colombia. Vol. 5. No. 25, (1871): 28-80.

Safford, Frank. El ideal de lo práctico: el desafío de formar una élite técnica y empresarial en Colombia. Bogotá: Universidad Nacional de Colombia y El Áncora, 1989. 
Samper, José María. "Prólogo". En Peregrinación de Alpha, de Manuel Ancízar. Bogotá: Universidad Nacional de Colombia, 2007. 9-21.

Sanín Cano, Baldomero. Letras Colombianas. México: Fondo de Cultura Económica, 1944.

Say, Jean-Baptiste. Tratado de Economía Política o Exposición sencilla del modo con que se forman, se distribuyen y se consumen las riquezas. (J. Sánchez Rivera, Trad.) Burdeos: Imprenta de Lawalle, 1821.

Say, Jean-Baptiste. Catecismo de economía política ó instrucción familiar: que muestra de qué modo se producen, distribuyen y consumen las riquezas en la sociedad. Madrid: Imprenta de Albán, 1822.

Villamil Ardila, Carol. Aproximación Histórica a la Facultad de Derecho, Ciencias Políticas y Sociales de la Universidad Nacional de Colombia. Bogotá: Universidad Nacional de Colombia, Facultad de Derecho, Ciencias Políticas y Sociales, 2001.

\section{Citar este artículo}

Chaparro, Germán Raúl. "Manuel Ancízar y la enseñanza de la economía política". Revista Historia de la Educación Colombiana. Vol. 24 No 24 (2020): 181-218

DOI: https://doi.org/10.22267/rhec. 202424.78 